\title{
La Visión del Mundo en el Lunario Sentimental
}

$\mathrm{E}^{\prime}$ L conjunto de composiciones en el Lunario sentimental se divide en tres partes diferentes en cuanto a la forma y el contenido. La primera consta de treinta y cuatro poemas esencialmente caricaturescos. La segunda incluye cuatro escenas dramáticas donde abundan seres y hechos sumamente fantásticos. La tercera son los cuatro cuenłos románticos y melancólicos intercalados a lo largo de las primeras dos divisiones.

El Lunario sentimental, por lo tanto, no es lo que podemos llamar una obra coherente en el sentido común del vocablo. Desde este punto de vista, sus tres divisiones podrían separarse como libros distintos. No existen relaciones palpables entre la familia burguesa de "Los fuegos artificiales", el enamorado de la luna en "La novia imposible", y el hada que mora en la fuente encantada de "Los tres besos". Las únicas constancias aparentes entre las tres divisiones son la redundancia de ciertos vocablos y la presencia ubicua de la luna.

¿Por qué, entonces, es el Lunario sentimental una obra íntegra y no dos o tres libros diferentes? El Lunario sentimental constituye una unidad artística porque su autor refleja siempre la misma percepción de la vida. Los diversos elementos que aparecen en la superficie de la obra se enlazan internamente por la verdad de aquella vida contra la cual Lugones quiso vengarse. Lo caricaturesco, lo fantástico y lo melancólico del Lunario sentimental difieren en cuanto a la forma y el contenido; pero en el fondo todo equivale a una esencia común.

Proponemos en este estudio: I) analizar las categorías mencionadas como elementos externamente diversos; 2) extraer el vínculo interno que funda a los thismos en entidad artística. 


\section{LA CARICATURA}

Las treinta y cuatro composiciones que forman la primera división del Lanario sentimental aparecen saturadas de grotescas distorsiones relativas, en la mayoría de los casos, a la luna, al hombre mediocre, al amor, y a la ciencia.

La participación de la luna como elemento caricaturesco se manifiesta en casi todos los poemas. Propone Lugones en el "Prólogo" dedicar el libro a la luna, y debidamente procura que la intervención del astro sea omnipresente.

En el poema inicial Lugones se burla de la crítica adversa y le ofrece el "luminoso huevo" de la luna en "manjar dulce y nuevo". "Jaculatoria lunar" define al astro con estos términos derogativos:

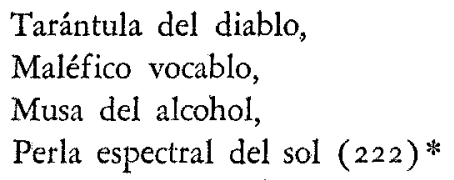

Pero es en el comiquísimo "Himno a la luna" donde más se concentran las distorsiones caricaturescas de la protagonista principal. Comienza el poema con fingidos elogios en los cuales se dirige el poeta a la luna llamándola "ilustre anciana de las mitologías". Pero poco después ofrece al astro completamente estéril en forma de esqueleto. Compara su porosa estructura a un hueso fósil, y su topografía a maxilares de calavera. Describe su fisionomía esférica como: "ampolla de alabastro"; "ojo sin iris tras anormal pestaña"; "lenteja de un péndulo inmenso"; "inexpresable cero en lo infinito"; "ombligo del universo"; "azufrado rostro sin orejas que sugiere la faz lampiña de un mandarín de afeitadas cejas".

Los restantes poemas completan el cuadro caricaturesco. Aparece en ellos una luna hecha de azúcar, remolacha, tapioca, queso, y otros comestibles. Frecuentemente sufre graves enfermedades y se presenta Łísica, flacucha, pálida, y aun con los colores macabros de un feto en alcohol. Otras veces se convierte en utensilios de cocina, entre los cuales figura un sartén donde el poeta declara que "frie cráneos sabios en luz del sol".

* Leopoldo Lugones, Obtas poéticas completas (Madrid: A. Aguilar, editor, 1959), p. Todas las citas siguientes se toman de esta edición. El número al finà de la cita indica la página a que corresponde. Para evitar conglomeraciones de números, limitaremos nuestras referencias a las citas centradas. 
La humanidad mediocre constituye otro elemento importante del ambiente caricaturesco en la primera parte del Lunario sentimental. Aparece a lo largo de todos estos poemas una rica variedad de tipos corrientes que se deforman ridículamente en la insipidez de su estado social. Son "estos: solteronas, lavanderas, bebés, nenés, nodrizas, pescadores, borrachos, tontos, necios, guías, viajeros, cocineros, mercachifles, sastres, tintoreros, ujieres, rentistas, bañistas, novios y novias, boticarios, maestros, familias, colegialas, y hasta un ahoracado que "templa en do re mí su soga".

También abundan objetos cotidianos que verdaderamente carecen de contenido estético: escarpines, corbatas, calzones, camisas, gorros, pijamas, batas, chinelas, corpiños, pañuelos, pañales, sandalias, chanclas, cazuelas, sartenes, ollas, cubos, cafeteras, caserolas, bicicletas, tranvías, camas, bañaderas, escobas, brochas y navajas de afeitar, lociones, cascos de botella, ovillos. El grupo de comestibles comunes incluye: el queso, la tapioca, la gelatina, el jamón, la leche, la chuleta, la miel, la harina, el vinagre, la fritura, el espárrago, el cacao, frutas, el bizcocho, el huevo, el grano, la sopa, almuerzos, salsas, comidas a la carta.

En el ya citado "Himno a la luna" una rentista obesa se describe de esta jocosa manera:

La rentista sola

Que vive en una esquina

Redonda como una ola,

Al amor de los céfiros sobre el balcón se inclina;

$Y$ del corpiño harto estrecho

Desborda sobre el antepecho

La esférica arroba de gelatina ( $2 \times 1$ ).

En el mismo poema un sastre expulsado de su tienda por lumbagos insomnes bosteza a la luna con "boca y axilas". Por otra parte aparece un hipocondríaco célibe que "deshoja su corazón" contemplando carteles donde chicas de "piernas internacionales" anuncian "entre cromos rivales lociones y bicicletas".

Pero es quizá en el poema "Los fuegos artificiales" donde mejor Lugones caricaturiza al hombre común. La situación que describe el poema se desarrolla de noche, en una plaza pública ocupada por una muchedumbre que celebra su día patrio presenciando un espectáculo pirotécnico. 
Estallan los primeros cohetes sobre la "O vocativa de las bocas abiertas", y según Lugones "abandonan más de una cabeza la cordura y las gorras". Bajo las luces de los fuegos, una familia burguesa forma este graciosísimo cuadro:

Mi musical vecina,

Hacia su mamá se inclina

$Y$ una llama loca

Del candente aparato

Con lúgubre sulfato

Le amorta la boca.

A su lado el esposo, con dicha completa,

Se asa en tornasol, como una chuleta;

Y el bebé que fingía sietemesino chiche,

No es ya más que un macabro fetiche.

La nodriza, una flaca escocesa,

$\mathrm{Va}$, enteramente isósceles, junto a la suegra obesa (260).

Los mismos fuegos los ridiculiza el poeta llamándolos: "áurea polvareda", "meteoro impresionista", "incadescente caspa". Y como toque final, se dirige con fingido elogio al inventor de los fuegos y exclama:

¡Oh maestro!, que hiciste tal maravilla

Con un poco de mixto, de noche y de mal gusto (257).

Otro elemento caricaturizado en el Lundrio sentimental es la ciencia moderna, especialmente la medicina. Esta caricatura, contraria a las otras, se desarrolla indirectamente. No hay distorsiones directas de médicos, químicos, biólogos, matemáticos, o astrónomos, El cuadro caricaturesco de la ciencia se traza mediante la aplicación de términos técnicos a situaciones o criaturas generalmente distanciadas del convencional mundo científico. Se relaciona esta caricatura con la de la humanidad mediocre, ya que en su aspecto práctico las ciencias aludidas intervienen en la vida cotidiana del hombre común moderno.

La medicina, hemos dicho, es la ciencia que más participa en las 
caricaturas del Lunario sentimental. Casi una tercera parte de los numerosos vocablos científicos que aparecen en la obra pertenecen a la terminología médica.

El "Himno a la luna" of rece el siguiente ejemplo al describir la superficie blancuzca del astro:

Carnes de espárrago que en linfática miseria

La tenaza brutal de la tos arranca (207).

En el mismo poema aparece un hipocondríaco célibe, un transeunte taconeando un caso quirúrgico, un enfermo febrífugo, y un sastre insomne que padece dolores lumbares.

El "Nocturno" presenta a una luna enfermiza con sus dolencias técnicamente definidas:

Tu dulce anemia,

Luna de idilio,

Allá se yerma

La frágil Filis

Trocando en bilis

Tu luz enferma (244).

En el poema inicial, "A mis cretinos", el poeta, después de ofrecer a sus críticos la luna como manjar, les hace esta advertencia:

Más con mueca importuna

No desdeñéis el plato,

Si lo hacéis, por remedio

De tan tosca dispepsia,

Os pongo en catalepsia

Durante siglo y medio (199).

La intervención de la geometría como elemento caricaturesco puede apreciarse en las siguientes escenas: los abultados senos de una señora gorda constituyen una "esférica arroba"; la fisionomía de una hiena es oblicua; la posición de un murciélago es tangente; la luna sube al cenit como "plenitud oblonga"; dos personas caminando juntas van "entera- 
mente isósceles"; un espectáculo pirotécnico equivale a "magnífico dodecaedro"; las olas de un mar sereno forman "simétrico rizo".

La astronomía aparece, claro está, principalmente en caricaturas relacionadas con la luna. El poeta se dirige al astro repetidas veces llamándole "astronómica ventana", "astronómica siempreviva", "postigo de los eclipses". En su apogeo la luna es una "sportwoman" que "dirige su cabriolé por zodíacos y eclípticas". Cuando desciende del cenit sufre la suerte del ave que cae al mar de cabeza derribada por una "batería de telescopios".

Interviene la química en escenas como ésta tomada del poema "Divagación lunar":

Quiero mezclar a tu champaña,

Su luz, en sensación extraña

De jarabe hidroclórico (240).

Ejemplos de la participación de la biología y la anatomía son respectivamente, "deidad ovipara" y "paradójica dendrita", términos empleados por el poeta para dirigirse a la luna.

Tanto caricaturiza Lugones en los primeros poemas del Lunario sentimental, que ni siquiera el ser amado escapa a sus graciosas distorsiones. En el poema "Divagación lunar" el poeta comenta de su amada:

Tu crueldad virginal se sutiliza;

$Y$ con sumisión postiza

Te acurrucas en pérfido mimo,

Como un gato que se hace una bola

En la cabal redondez de su cola (242).

Luego clasifica su comportamiento como "intriga de pequeño mamífero rosa", y le echa toda la culpa a la luna.

\section{EL ESDRÚ JULO COMO CATALISTA CARICATURESCO}

Una de las características de estilo más notables en el Lunario sentimental es la gran cantidad de vocablos esdrújulos que el poeta emplea en combinación con palabras llanas. Dicha combinación surge unas 400 
veces. Más o menos 250 de los casos, o sea, un 63 por ciento, son combinaciones de adjetivos esdrújulos y sustantivos llanos, el adjetivo antecedente del sustantivo: "anómalo pichoncito"; "anacrónica brasa". Otros 80 casos, un 20 por ciento, aparecen con el adjetivo esdrújulo detrás del sustantivo llano: "dones acuáticos"; "oso misántropo". En 40 casos, un Io por ciento, el sustantivo es el esdrújulo y precede al adjetivo llano: "éxtasis supremo"; "primogénita delgada". Los restantes 20 casos, un 5 por ciento, son combinaciones de adjetivos llanos delante de sustantivos esdrújulos: "silencioso ébano"; "claro témpano".

Hay además de dichas combinaciones, otra cantidad, mucho menor, pero significativamente copiosa, de adjetivos y sustantivos esdrújulos: "crustáceo violáceo"; "orquídea congénere".

$\mathrm{Y}$ a todos estos casos podemos añadir aun otro copioso número de esdrújulos que no participan en combinaciones, pero que aparecen contiguos a partículas, adverbios, o formas verbales.

Las estructuras de vocablos esdrújulos y llanos en combinación se concentran en los poemas caricaturescos de la primera parte de la obra, sobre todo en escenas donde se intensifica la distorsión.

Consideremos como primer ejemplo el poema inicial, "A mis cretinos", donde el poeta se burla de sus críticos antagonistas of reciéndoles una luna completamente deforme. Llama la obra su "lírico proyecto", y anuncia "poéticos tributos" que propone rendir a la luna, su "astronómica dama" o "intima planchadora". Añade que su "poético exceso" es queso para el buen gusto de la crítica, y que el "luminoso huevo" del astro, como "deidad ovípara", será para ellos una "cena opípara". Y si a los "líricos doctores" le hace daño el plato, entonces los pondrá a todos en catalépsia, para lograr en "rasgo específico" un "silencio magnífico" de academia y retórica.

El "Himno a la luna" citado en párrafos anteriores es, sin duda, la composición del Lunario sentimental que contiene más cuadros caricaturescos. Es significativo que 56 casos de vocablos esdrújulos en combinaciones con voces llanas, y unos 25 esdrújulos fuera de dicha combinación, se encuentran en este poema. Veamos algunos ejemplos: "litúrgico furor" llama el poeta a las orgías mediante las cuales culturas primitivas rendían culto a la luna; un borracho que cae al mar sufre un "excéntrico descalabro"; los versos del mismo Lugones son "gárrulo caudal"; un lunático enamorado de la luna cuenta al astro entre sus "quiméricas novias"; la criatura que empolle del huevo de la luna pertenecerá a un "olímpico linaje"; alguien que contempla el astro tristemente equivale a "romántica 
criatura": que en "diplomática blancura" suspira algún "trágico evento"; los sauces de la ribera sufren "poéticos desmayos" y echan al agua anzuelos para pescar rayos de luna convertidos en sardinas; la blancura de la luna consta de "carnes de espárrago"; senos abultados equivalen a "esféricà arroba"; los pasos de un transeunte taconean un "quirúrgico caso"; las modelos de carteles son "aéreas coquetas"; leones bramando en coro expresan "quejas bárbaras"; sufrir cuitas de amor es padecer en un "erótico crucifijo"; gallos que cantan antes de tiempo son "gallos anacrónicos". La misma luna equivale a: "púdica monja"; "hipnótica prisionera"; "ebúrneo mingo"; "lóbrega linterna"; "témpano prematuro"; "paradójica dentrita"; "péndulo inmenso"; "astronómica siempreviva"; "verónica"; "semáforo".

En "Divagación lunar" propone el poeta, como buen "astrónomo teórico", mezclar en la champaña de su amada un poco de "jarabe hidroclórico" para que ésta se envenene con la "pálida mixtura". Luego trata su "pérfido mimo" como intriga de "mamífero rosa", y acusa a la luna de poner un "detalle trágico" en su comportamiento.

Se ha citado el poema "Los fuegos artificiales" como una concentración de escenas caricaturescas relativas a la humanidad mediocre. Contamos en esta composición unos 36 adjetivos y sustantivos esdrújulos combinados, respectivamente, con sustantivos y adjetivos llanos, y otros ro esdrújulos fuera de dicha estructura.

He aquí algunos casos: "paganismo atávico" e "impetu bellaco" llama el poeta al comportamiento colectivo de la concurrencia que presencia el espectáculo pirotécnico; la consorte de un señor se exalta con "mágico transporte" bajo las luces multicolores de los fuegos; la luna, mientras tanto, llora en la "acuática lejanía"; los cohetes estallan con "estrépito salvaje". El espectáculo mismo se describe como "astronómica feria"; "química hoguera"; "magnífico dodecaedro"; "múltiples dardos"; "anacrónico instante de aurora"; "patrióticos fuegos"; "seráficos añiles"; "lúgubre sulfato"; "anacrónica brasa"; "último bocado".

La gran mayoría del tipo de combinaciones citadas aparece, como ya se ha dicho, en los poemas caricaturescos que forman la primera parte del Lunario sentimental. Las quiméricas escenas teatrales y los cuentos románticos que constituyen las restantes divisiones del libro apenas contienen análogas estructuras. Dicha desproporción inevitablemente educe la conclusión de que los esdrújulos en combinaciones con vocablos llanos desempeñan un papel importante en la técnica caricaturesca del Lunario sentimental. 
Aparentemente, la característica del esdrújulo propicia a la caricatura se encuentra en su acentuación. El oído español, acostumbrado a vocablos llanos, sin duda percibe voces esdrújulas como sonidos discordantes. El esdrújulo, entonces, equivale a una distorsión de la usual acentuación llana en español. La caricatura es también distorsión. No tiene nada de extraño, por lo tanto, que un poeta como Lugones, que conoció tan a fondo los secretos de su letngua combinara con su caricatura catalistas esdrújulos con el fin de realzar distorsiones.

Los abultados senos de la ya aludida rentista obesa indiscutiblemente sufren distorsiones caricaturescas si se describen como "redonda arroba de gelatina". Pero cámbiese el adjetivo "redonda" por "esférica" y se notará cómo la distorsión se torna mucho más ridícula: "esférica" arroba de gelatina". El mero hecho de introducir un sonido discordante en una escena ridícula intensifica considerablemente el ambiente grotesco de la misma. Obsérvense otros ejemplos: "mala chuleta" y "sórdida chuleta"; "uraños orangutanes" y "misántropos orangutanes"; "mojados panales" y "líquidos pañales".

La posición del esdrújulo en relación con la voz llana es también significativa. La voz esdrújula entra en combinación con la palabra llana a manera de contraste. El sonido discordante del esdrújulo suena aún más discordante si el vocablo se encuentra inmediatamente contiguo a una corriente palabra llana. Nótese: "el hipocondriaco que moja su pan de amor" y "el impetu bellaco encanalla acritudes de tabaco"; "suspiráculo de las novias" y "hudió su excéntrico descalabro".

$Y$ el efecto discordante del esdrújulo se acentúa todavía mejor si un adjetivo esdrújulo precede a un sustantivo llano. Recuérdense que un $6_{3}$ por ciento del conjunto de estructura esdrújulo-llana aparece conforme a dicha combinación. Compárense algunas combinaciones de adjetivos esdrújulos delante de sustantivos llanos con las inversiones de las mismas: "astronómica feria" y "feria astronómica"; "mímicas morondangas" y "morondangas mímicas". La mayor efectividad de las primeras combinaciones se debe al hecho de que el adjetivo descriptivo delante del sustantivo equivale también a distorsiones del habla común, esta vez sintacticales. Lo usual es que el adjetivo descriptivo aparezca detrás del sustantivo. Lugones, sin duda, lo coloca delante para producir una discordancia sintactical que colabora con la discordancia fonética del esdrújulo como catalista en la producción de caricaturas.

Existe, a propósito, una curiosa paradoja en el Lunario sentimental relativa al uso de palabras. Por un lado hay una enorme riqueza de voca- 
bulario. Casi todas las composiciones, tanto en verso como en prosa, contienen numerosos neologismos, argentinismos, y voces extranjeras: "suspiráculo", objeto recipiente de suspiros; "cachivache", persona u objeto inútil; "cold cream". Hay, sin embargo, a pesar de dichas tendencias inovadoras, ciertos vocablos corrientes en español que se repiten con redundante frecuencia. Un buen ejemplo de este aspecto tautológico se puede hallar en las 4 10 combinaciones de voces esdrújulas y llanas arribas mencionadas. Más de una cuarta parte de estas estructuras, o sea, unos r ro casos, emplea sólo doce adjetivos esdrújulos. Son éstos, en orden de mayor frecuencia: "lúgubre", I7; "pálido", I5; "lírico", тo; "último", 9; "pérfido", 8; "lóbrego", 8; "mágico", 7; "intimo", 7; "astronómico", 7; "lánguido", 6; "líquido", 6. Estos mismos adjetivos esdrújulos también aparecen con frecuencia fuera de combinaciones con sustantivos llanos. Otros vocablos muy usados son los sustantivos "mimo", "témpano", "misántropo", "misantropia", y los adjetivos "gátrulo", "anómalo", "anacrónico". Obsérvese que la mayoría de éstos tambièn son esdrújulos.

\section{EL ANIMAL COMO ELEMENTO CARICATURESCO}

La población zoológica del Lunario sentimental es representativa de diversas especies domésticas y salvajes. Muchos de estos animales son verdaderos. Otros existen indirectamente en tropos. En el género de animales caseros contamos doce gatos y siete perros, machos y hembras. Pollos, gallos, gansos, ocas y cisnes constituyen el grupo de aves domésticas. La representación de bestias campestres incluye: bueyes, asnos, pollinos, chivos, vacas, zánganos, caballos, cabras, borricos, jamelgos, ovejas, corderos, potros, reses, burritos. En el género de mamíferos salvajes aparecen: monos, gorilas, osos, lobos, jirafas, zorros, tigres, orangutanes, leones, chacales, hienas, elefantes. El grupo de aves silvestres incluye: aves, garzas, alondras, avestruz, faisán, buhos, lechuzas, pajarillos. Las criaturas acuáticas del libro son: el tiburón, la sardina, la trucha, la madreperla, el pez, el crustáceo. La rana y el carey son los únicos anfibios representados. En el género de bichos encontramos: cigarras, grillos, tarántulas, carcoma, moscas. Hay sỏlo dos animales exóticos: el camello y el dragón. Las restantes criaturas se limitan a murciélagos y moluscos.

El papel que desempeña esta miriada de criaturas zoológicas no puede ser más obvio. Los animales del Lunario sentimental, en la mayoría de 
Ios casos, equivalen a distorsiones caricaturescas. Casi todos se concentran en los poemas caricaturescos de la primera parte del libro.

Numerosas caricaturas de la humanidad mediocre, por ejemplo, se trazan por medio de comparaciones de hombres con animales o animales con hombres. Veamos las siguientes escenas:

El can lunófilo, en pauta de maitines,

Como una damisela ante su partitura,

Llora enterneciendo a los serafines

Con el primor de su infantil dentadura (212).

Las crasas ocas,

Regocijo de la granja,

Gritan como colegialas locas

Que ven pasar un hombre malo (214).

Otras veces la caricatura se logra mediante fundiciones de personas $y$ bestias. Entonces aparece el ser humano con características zoológicas y el animal con cualidades humanas:

Desde sus islas moscadas

Misántropos orangutanes... (2 10)

Los lobos de agudos rostros judiciales,

La democracia de los chacales... (213)

Ella tiene los mimos de rubia gata (289)

Se desgañita pisado en la cola (255),

Con ayes de mujer, un can intruso.

También la luna sufre diversas deformidades mediante comparaciones con criaturas zoológicas:

La luna cruza el azul pleno (24r)

Como una trucha...

En la gracia declinante de tu disco

Bajas acompañada por el lucero 
Cual una oveja por su cordero (2I2).

\section{TEATro quimérico}

Bajo el título de "Teatro quimérico" Lugones agrupa las cuatro escenas dramáticas que forman la segunda división del libro. Toda esta sección pertenece a un mundo fantástico muy alejado de las distorsiones caricaturescas que ocupan los poemas de la primera parte. Dos de las escenas, "El Pierrot negro" y "Dos ilustres lunáticos o divergencia universal" están escritas en prosa. En las otras, "La copa inhallable" y "Los tres besos", dialogan en verso.

La acción de "Dos ilustres lunáticos" ocurre en una estación de ferrocarril a las once de la noche. Hay sólo dos personajes. Uno es "rubio, bajo y lampiño, tirando a lo obeso, pero singularmente distinguido". El otro "gallardea un talante alto y enjuto; una cara aguleña puro hueso". No se conocen ni jamás se han visto. Entablan conversación para pasar el tiempo, y a medida que se desarrolla el diálogo los interlocutores revelan personalidades diametralmente opuestas. El caballero rubio es cínico y materialista. El señor enjuto es idealista y cree en la inmortalidad del alma. El rubio, un socialista práctico. Sufrió un desengaño amoroso y ahora desdeña a las mujeres. El señor enjuto muestra tendencias anarquistas y ama a una mujer que no conoce. Los interlocutores se van irritando a medida que defienden sus opiniones opuestas. Llega la disputa a su apogeo cuando el rubio escupe hacia la luna, "doncella desamparada" que el señor enjuto defiende. Se retan los personajes a un duelo. Pero al cambiar tarjetas de identidad, sus enojos se truecan en asombro. Lee el materialista: "Alonso Quijano". Lee el idealista: "El príncipe Hamlet". Don Quijote y Hamlet simultáneamente alzan los ojos, pero advierte cada uno que su interlocutor ha desaparecido.

"El Pierrot negro" es una pantomima en cuatro cuadros que trata ciertos infortunios sufridos por el personaje del título. La acción es la siguiente: Pierrot, desdeñado por Colombina, cae en un tacho de pintura negra. Pide a un tintorero que lo destiña, pero éste no conoce substancia que pueda hacerlo. Polichinela, rico en experiencia y sabiduría, dice que no hay nada en la Tierra que lo pueda desteñir, y le aconseja que sólo un viaje a la luna, reino de blancura, corregirá su defecto. Pierrot toma el consejo del sabio jorobado y va al laboratorio de un alquimista a buscar el remedio. El alquimista primero trata de desteñir a Pierrot por 
medio de un nuevo amor. Prepara una fórmula mágica con la cual educe la presencia de la Sílfide y las ninfas de la Tierra. Pero Pierrot reacciona negativamente e insiste en el viaje a la luna. El alquimista por fin cede y entrega a Pierrot un telescopio y una escoba. Pierrot se monta en la escoba y sale volando hasta llegar a la luna. Camina largo rato por el astro, pero no logra ponerse blanco. Luego se enfurece cuando oye la risa de Colombina y regresa a la Ticra. Al pasar por las nubes blancas del planeta recupera su color natural. Unos guijarros que había recogido en los campos de la luna se han transformado en diamantes. Colombina desdeña el tesoro y busca amorosa los labios de Pierrot.

"La copa inhallable" es una égloga en un acto. La acción se desarrolla en un monte de Arcadia. Anfiloquio, escultor, busca una modelo para una estatua con la cual propone cumplir un voto a la diosa Diana. Agenor, pastor viejo, vive en una cabaña al pie del monte con sus dos hijas, Nais e Iole, y su sobrino Darío, cabrero de quince años. Darío quedó huérfano al nacer y Agenor se encargó de su crianza. El bebé, sin embargo, no era macho, sino hembra. El dios Pan le había dicho a Agenor que criase a la niña como niño hasta que cumpliera los quince años, pues era su destino que "causara a los tres lustros, una dicha y dos penas". El pastor, obediente a la orden del dios, cambió el nombre de la niña de Daria a Darío, y la crió como macho. Las hijas del pastor hace tiempo que están enamoradas de su primo. Lo besan tiernamente y le ofrecen sus encantos físicos. Pero ya Darío ha cumplido sus quince años y tiene que revelarles la verdad de su sexo. El cabrero se abre el jubón y muestra sus senos de doncella. Nais e Iole sufren reacciones negativas. Dario, ahora Daria, se desmaya, y las muchachas ansiosas de venganza, abandonan a la pastora para que se la coman los lobos. Las dos penas del agüero se acaban de materializar. Más tarde Agenor y Anfiloquio encuentran a Daria desmayada en la arboleda. Su entreabierto jubón revela infinitos encantos femeninos que inspiran amores en el escultor. Daria será su modelo, y la dicha del agüero se cumple.

"Los tres besos", un cuento de hadas, también se desarrolla en un ambiente bucólico. La acción gira en torno de la siguiente leyenda:

Cuando la luna estaba más próxima a los cielos Bajaron de la luna dos ángeles gemelos.

De aquel candor celeste, que instruidos por todo

Lo humano, los gemelos encontráronse un día 
Roídos de pasiones y de filosofia;

$\mathrm{Y}$ como el ser angélico de la ilusión depende,

Transformátonse de ángeles en un hada y un duende.

Su bondad defraudada se volvió maleficio ( 380 )

Y haciendo su morada la fuente más pura,

Abrieron el período de una eterna tortura

... mas si algún peregrino

Se aproxima, en el fondo, cuando va a beber,

Mira un hada si es hombre y un duende si es mujer.

El amor, desde entonces, en su vida se aduna

Y después los amantes mueren del corazón.

La maligna pareja... ha de amar solamente

Al amante que pueda fijarlos con un beso (38I).

Los seres humanos que aparecen en el cuento ocupan gran parte de su tiempo en asuntos relativos al amor. Dos de ellos, Reinaldo y Graciana, terminan enamorados. Los hermanos Dalinda y Jacinto, a besos, logran sacar al duende y al hada de la fuente encantada. Se concierta el amor entre ellos, y se van en feliz matrimonio a vivir en la luna. El tercer beso del cuento corresponde a Calixto, criado antipático constantemente regañado por los jóvenes enamorados. Calixto un día mete la cabeza en la fuente encantada y surge con una bellísima cresta de gallo. La única manera que puede deshacerse de la cresta es recibiendo un beso de amor. Pero como nadie lo quiere besar, hurta un beso de Graciana cuando ésta ofrece a su amante una cereza con la boca. El criado sufre un "sonoro cachete" por su atrevimiento, pero pierde la cresta y queda feliz.

\section{LOS CUENTOS ROM:ÁNTICOS}

La tercera división de Lunario sentimental consiste de cuatro cuentos románticos, tres intercalados entre los poemas caricaturescos de la primera parte, y uno al final del libro, después del "Teatro quimérico". El ambiente de estos cuentos es sumamente melancólico. Recuerdan en muchos aspectos a las leyendas de Bécquer. Los caracteres, sufridores por excelen- 
cia, voluntariamente rechazan asequibles dichas para consumirse en el dolor de su tristeza.

"Inefable ausencia" trata la reunión de dos enamorados seis meses distanciados. Roberto acaba de pasar una desagradable temporada en la finca de sus parientes. Detestaba la vida agreste. Prefería el ambiente intelectual de la ciudad. Había sufrido mucho aislado de su medio y del amor que lo esperaba. Pero el tiempo transcurte y llega al fin el día de la ansiada reunión. Robetto acaricia las manos de Blanca, su amada. Blanca reacciona tiernamente. Ambos experimentan ansias de contacto físico; pero al buscar el beso Roberto se da cuenta de que no ama a Blanca como antes. Sólo puede amarla en la distancia. "Si quería conservar la excelencia absoluta de su amor, tendría que alimentarlo en la soledad". Su único remedio es alejarse de ella. Decide, entonces, regresar a la odiada finca y permanecer distanciado para siempre. No besa a su amada al despedirse por no llevar consigo "ningún recuerdo cuyo encanto aminorara su sacrificio".

"Abuela Julieta" es la historia de un viejo amor que nunca se consuma. Emilio, caballero de cincuenta años, y su tía Olivia, anciana de setenta años, se han amado en silencio mucho tiempo. Olivia sintió su primera pasión por el sobrino cuando éste contaba sólo diez años de edad y ella cumplía los treinta. Emilio ama a su tía desde niño. Ambos son célibes y misántropos. La diferencia de edades había concluido por desaparecer para ellos, "tenían las cabezas blancas y esto les bastaba". "Los martes y los jueves eran días de ajedrez en casa de la señora Olivia, y Emilio concurría asiduamente desde hacía diez años". Sus pensamientos estaban completamente compenetrados, pero nunca manifestaron señal alguna de amor. Una noche ambos sienten simultáneas ansias de confesar su pasión oculta. Intentan hablar. Pero un rayo de luna da sobre las canas de Olivia. Emilio contempla a su tía y recuerda que también sus cabellos son blancos. Sin darse cuenta ha pasado la vida. El amor entre ellos ya no es más que una ilusión irremediablemente perdida.

"La novia imposible" trata de la tragedia de un melancólico joven locamente enamorado de una quimera. Un comandante traba amistad con un muchacho rico y soltero. El joven siempre padece profundas tristezas y manifiesta tendencias de suicida. No puede querer. El único amor posible para él es el amor imposible, por eso está condenado al aniquilamiento. Desde niño soñaba con quimeras. Tenía un amigo imaginario. Conversaban y se contaban sus percances. Pero un día lo mató, y desde entonces vive en la soledad. El comandante tiene que salir de la ciudad. Pasan dos 
años. Cuando regresa, encuentra al melancólico joven arruinado, pero profundamente feliz. Tiene una amante. Esa misma noche dormirá con ella en las aguas de un estanque. Cuando llegue la noche dormirá con la luna.

"Francesca" cuenta la tragedia de una muchacha desposada por engaño con un corcovado monstruoso. Francesca contaba sólo diez y seis años de edad. El corcovado horriblemente contrahecho de cuerpo y alma, manda a su hermano, Paolo, a casarse por poder suyo. Paolo es guapo, culto, cortés, valeroso caballero. Una dama hace creer a Francesca que este es el esposo, y la joven felizmente acepta la oferta matrimonial. La noche de bodas el corcovado recibe a Francesca en una habitación oscura, donde se consuma el matrimonio sin que la muchacha se dé cuenta del engaño. Cuando despierta por la mañana, siente horror al conocer a su verdadero esposo. Pasan diez años. Francesca detesta al corcovado. Hace tiempo que vive enamorada de Paolo, y éste de ella, pero nunca han confesado su amor. Se aman en silencio, con la mirada. El corcovado se entera, reacciona con afanes de venganza, que finalmente culminan con el asesinato de los amantes.

\section{LO REAL Y LO IRREAI.}

Bien se puede apreciar por los temas hasta ahora expuestos, que las tres divisiones de Lunario sentimental difieren fundamentalmente en cuanto a la forma y el contenido. Es obvio que la caricatura, la melancolia, y los cuentos de hadas no pertenecen al mismo género. Sin embargo, toda esta diversificación constituye una inquebrantable unidad artística, ya que las tres divisiones del Lunario se enlazan en el fondo por el concepto de la vida que tuvo Lugones al componer su obra.

Y este concepto ¿qué consiste? Cambiemos la perspectiva analítica de este estudio para hallar la respuesta.

Toda caricatura contiene dos elementos: el objeto caricaturizado y la distorsión caprichosa del mismo. La caricatura de la rentista obesa en el "Himno a la luna" consiste de una señora gorda de abultados senos apoyada en su balcón, y de otra señora en posición análoga derramando de su pecho una "esférica arroba de gelatina". Una caricatura de la luna en el mismo poema consiste del astro tal como es, y de otra luna que tiene la forma de un "ojo sin iris tras anormal pestaña". La amada en "Diva. gación lunar" es una mujer mimosa, y al mismo tiempo un gato acurrucado a manera de bola. La caricatura, en otras palabras, es una dualidad formada por la realidad y un reflejo irreal que la remeda. 
En la primera división del Lunario sentimental la realidad y la irrealidad, lo verdadero y lo imposible, manan por los poemas lado a lado como líneas paralelas, acercándose y distanciándose de acuerdo con la distorsión caricaturesca. Consideremos como ejemplos algunas de las ya citadas comparaciones de animales y personas:

El can lunófilo, en pauta de maitines,

Como una damisela ante su partitura... (21:2)

Misántropos orangutanes... (210)

Las crasas ocas,

Gritan como colegialas locas... (214)

En el primer caso la realidad se mantiene distanciada de su reflejo caricaturesco. La damisela y el can se parecen, pero ambos conservan su identidad propia. El can es animal y la damisela es persona. En el segundo ejemplo la realidad y la irrealidad hacen contacto. El ser humano, lo caricaturizado, se funde con el orangután, su caricatura. Aparece entonces el animal con características humanas. En el tercer ejemplo la realidad y la irrealidad aparecen juntas, pero luego se separan. Las "crasas ocas" son aves domésticas con cualidades humanas; pero si gritan como colegialas, entonces las alborotadas criaturas y las muchachas caricaturizadas mantienen su identidad propia.

En paralelismos análogos lo real y lo irreal manan a través de las restantes divisiones del libro. La única diferencia es que en estas divisiones el aspecto irreal no corre por el plano de la caricatura.

"Dos ilustres lunáticos" resucita a dos personajes de la ficción de antaño y los presenta en una moderna estación de ferrocarril. Hamlet viste zapatos de charol y fuma cigarrillos turcos. Don Quijote viste un traje gris que le sienta mal. Discuten de política y problemas sociales pertenecientes a la primera década del siglo xx. Hamlet es materialista, cínico, realista. Su concepto de la vida es impersonal, científico. Don Quijote, idealista por excelencia, es todo lo contrario. Percibe la vida no como es, sino como quiere que sea.

"La copa inhallable" contiene una ambigüedad sexual. El pastor Darío no es pastor, sino pastora. Sus primas, inocentes del engaño, viven enamoradas de un ser que no existe. Cuando Darío se convierte repentina- 
mente en Daria, las muchachas sufren un terrible desengaño. El escultor Anfiloquio, sin embargo, se enamora de la pastora y logra la felicidad que ansiaba. Aquí la dicha y la desdicha se enlazan con los paralelos de lo real y lo irreal. También es significativa la dualidad entre los pastores, personas verdaderas, y los seres mitológicos, Pan y Diana.

En "Los tres besos" el paralelismo es todavía más obvio. Un hada y un duende moran en una fuente encantada. Si una persona verdadera se mira en sus aguas, ve en el fondo la figura de un ser imposible. Los planos de la realidad y la irrealidad se miran cara a cara, y finalmente hacen contacto cuando Dalinda y Jacinto, a fuerza de besos, sacan a los quiméricos habitantes de la fuente.

En "El Pierrot negro" el famoso personaje de la Comedia del Arte aparece pintado de dos colores extremos: blanco y negro. La realidad, lo blanco, y la irrealidad, lo negro, repentinamente se juntan y se separan. Cuando Pierrot se pone blanco, los guijarros que trae se convierten en piedras preciosas, un nuevo plano de lo irreal.

En "Inefable ausencia" el protagonista Roberto distingue entre dos amores: el materialista y el ideal; el que se alimenta del contacto físico y el que medra en la soledad. También distingue entre dos ambientes sociales opuestos: la vida ruda del campo y la intelectual de la ciudad. Detesta la primera y considera la segunda la única de ser vivida. Al principio del cuento los planos realidad-irrealidad, dicha-tristeza se funden de esta manera: realidad con dicha e irrealidad con tristeza. Roberto se siente feliz al lado de su amada y desdichado con sólo el recuerdo de ella. Luego la fundición se deshace y los planos cambian posiciones diametralmente. Roberto ya no se siente feliz al lado de Blanca. Necesita regresar a la soledad de la odiada finca para conservar la "excelencia absoluta" de su amor. La combinación de paralelos es ahora la siguiente: irrealidad con dicha y realidad con tristeza.

"Abuela Julieta" contiene análogas dualidades de amor verdadero y amor ideal. Olivia y Emilio se han querido cuarenta años. Se ven con frecuencia. No obstante, ni el uno ni el otro declara, ni declarará jamás su pasión oculta. Aquí los planos de la ilusión y la verdad permanecen distanciados. Se acercan cuando ambos, simultáneamente, sienten deseos de revelar su secreto; pero como ninguno de los dos dice nada, los planos pronto se separan y regresan a su usual posición distanciada. Intervienen también importantes paralelos relativos al tiempo. El amor de Emilio y su tía corre hacia el mismo fin por direcciones situadas en el pasado y el futuro. La diferencia de edades entre tía y sobrino separa planos de tiempo 
que se distancia en narraciones del pasado y se juntan en la acción del presente. Hubo un tiempo en que Olivia le llevaba veinte años a su sobrino, pero en la actualidad del cuento la diferencia de edades había desaparecido.

"La novia imposible" también contiene dualidades de amor real y amor ideal. "El único amor posible para mí sería el amor imposible", declara el protagonista. El amor material fue lo primero que empezó a cansarle. Nunca había comprendido bien lo que significaba enamorarse como se enamoran los seres humanos. El reflejo de la luna en un estanque era su única novia posible. Otro paralelo significativo en el cuento se relaciona con el amigo imaginario que tenía el protagonista en su niñez. Conversaba con él y a veces se disgustaban. Figuraba que su mano izquierda era la suya. Un día que se la hirió no sintió dolor, pues el herido era el otro. Aquí la realidad y la irrealidad se integran en la estrechez de un solo ser. El protagonista y su amigo quimérico ocupan el mismo cuerpo. Luego se separan cuando el ser verdadero asesina a su creación, a manera de suicidio parcial.

En "Francesca" los planos de lo real y lo irreal primero se enlazan y luego se separan repentinamente. Francesca se casa con el corcovado creyéndose que el esposo es el joven y bello Paolo, hermano del marido verdadero. En su engaño goza algunos momentos felices, pero de pronto su dicha se convierte en desdicha al despertar de su noche de bodas con el corcovado a su lado. La combinación material-ideal del matrimonio se deshace pasando lo ideal al tácito amor de Paolo y Francesca y lo material permaneciendo en la legalidad social del odiado vínculo conyugal. Obsérvese que esta repentina separación de planos también aparece en "El Pierrot negro", "La copa inhallable" y "Los tres besos", respectivamente como cambios de color, de sexo, y de cresta.

\section{CONCLUSIÓN}

La integración del mundo material en un cosmos poético es un hecho imposible. Esta imposibilidad, terriblemente desconcertante para el espíritu omnisciente de Leopoldo Lugones, es la visión de la vida que el poeta tuvo cuando escribió el Lunario sentimental, $y$, consecuentemente, el vínculo interno que funde los diversos elementos de la obra en entidad artística. Dicha visión se manifiesta mediante un proceso dinámico de planos reales e irreales que manan a través del libro, chocando continuamente en inútiles afanes de unidad permanente. En La guevra gaucha y en Los crepísculos 
del jardin, Lugones logra la integración deseada. En el Lunario sentimental la fusión aparece irremediablemente deshecha. El núcleo psicológico de la obra es una constante actitud de desengaño y fracaso. El poeta ya no puede juntar sus dos mundos significativamente. Por eso se venga de la vida burlándose de la humanidad y de su propio ser.

En 1938 Leopoldo Lugones se quitó la vida. Nadie sabe por qué lo hizo. Probablemente nadie lo sabrá. Sería casi inútil indagar los motivos que tuvo Lugones para destruir su propia existencia. Nosotros creemos, sin embargo, que la frustración intelectual y espiritual que sufrió el poeta al no poder integrar la realidad con la irrealidad quizá haya contribuido en algo a la causa o causas inmediatas de'su suicidio. Con Odas seculares, en r9ro Lugones abandona para siempre sus paisajes cósmicos y comienza una nueva etapa de poesía directa y realista que había de prevalecer hasta su muerte, treinta años después. Pero es muy posible que el fracaso de no poder unir significativamente todas las dimensiones de su asombrosa inteligencia lo haya atormentado durante tres décadas.

El Lunario sentimental contiene dos composiciones en las cuales el protagonista se suicida o piensa en el suicidio, precisamente porque no puede integrar la realidad de la vida con una ilusión. "El pescador de sirenas", un poema caricaturesco, trata la tragedia de un infeliz empeñado en pescar los reflejos de la luna en un estanque. Sabe bien que las sirenas del estanque son meros reflejos, pero este conocimiento no lo desanima. Persiste en su tarea inútil, hasta que una noche:

Oye, naturalmente, el canto maldito, Arrojase - homérida - al agua sinfónica, Y como dirá la crónica, Pone fin a sus días sin dejar nada escrito. (229)

El protagonista del ya citado cuento, "La novia imposible", también se enamora de una luna reflejada en el agua. Declara el melancólico joven: "La idea del suicidio ha germinado más de una vez en mi cabeza, pero me he sentido cobarde". (306) "Estoy condenado al aniquilamiento, pues el único amor para mí sería el amor imposible". (305) "El amor no es tnás que un bello prólogo de la muerte". (306) 